European Journal of Public Health, Vol. 25, No. 2, 330-335

(C) The Author 2014. Published by Oxford University Press on behalf of the European Public Health Association. All rights reserved. doi:10.1093/eurpub/ckul67 Advance Access published on 18 September 2014

\title{
Unemployment, public-sector health-care spending and breast cancer mortality in the European Union: 1990-2009
}

\author{
Mahiben Maruthappu, ${ }^{1,2}$, Johnathan A. Watkins ${ }^{3}$, Mueez Waqar ${ }^{4}$, Callum Williams ${ }^{5,6}$, \\ Raghib Ali ${ }^{7,8}$, Rifat Atun ${ }^{9}$, Omar Faiz ${ }^{1}$, Thomas Zeltner ${ }^{10,11}$ \\ 1 Imperial College London, London SW7 2AZ, UK \\ 2 Faculty of Arts and Sciences, Harvard University, MA 02138, USA \\ 3 Institute for Mathematical \& Molecular Biomedicine, King's College London, London SE1 1UL, UK \\ 4 School of Medicine, University of Liverpool, Liverpool, Merseyside L69 3BX, UK \\ 5 The Economist, 25 St James's Street, London SW1A 1HG, UK \\ 6 Faculty of History, University of Oxford, George Street, Oxford OX1 2RL, UK \\ 7 Cancer Epidemiology Unit, University of Oxford, Richard Doll Building, Roosevelt Drive, Oxford OX3 7LF, UK \\ 8 Faculty of Medicine and Health Sciences, United Arab Emirates University, PO Box 17666, Al-Ain, United Arab Emirates \\ 9 Harvard University, MA 02138, USA \\ 10 Special Envoy for Financing to the Director General of the World Health Organization (WHO), Avenue Appia 20, 1211 \\ Geneva 27, Switzerland \\ 11 University of Bern, Gerechtigkeitsgasse 31, Bern, CH 3011, Switzerland
}

Correspondence: Mahiben Maruthappu, Faculty of Arts and Sciences, Harvard University, Cambridge, MA 02137, USA, Tel: +1 857294 6678, e-mail: maruthappu@post.harvard.edu

\begin{abstract}
Background: The global economic crisis has been associated with increased unemployment, reduced health-care spending and adverse health outcomes. Insights into the impact of economic variations on cancer mortality, however, remain limited. Methods: We used multivariate regression analysis to assess how changes in unemployment and public-sector expenditure on health care (PSEH) varied with female breast cancer mortality in the 27 European Union member states from 1990 to 2009. We then determined how the association with unemployment was modified by PSEH. Country-specific differences in infrastructure and demographic structure were controlled for, and 1-, 3-, 5- and 10-year lag analyses were conducted. Several robustness checks were also implemented. Results: Unemployment was associated with an increase in breast cancer mortality $[P<0.0001$, coefficient $(R)=0.1829,95 \%$ confidence interval $(\mathrm{Cl}) 0.0978-0.2680]$. Lag analysis showed a continued increase in breast cancer mortality at $1,3,5$ and 10 years after unemployment rises $(P<0.05)$. Controlling for PSEH removed this association $(P=0.063, \mathrm{R}=0.080,95 \% \mathrm{Cl}-0.004$ to 0.163$)$. PSEH increases were associated with significant decreases in breast cancer mortality $(P<0.0001, \mathrm{R}=-1.28,95 \% \mathrm{Cl}-1.67$ to -0.877$)$. The association between unemployment and breast cancer mortality remained in all robustness checks. Conclusion: Rises in unemployment are associated with significant short- and long-term increases in breast cancer mortality, while increases in PSEH are associated with reductions in breast cancer mortality. Initiatives that bolster employment and maintain total health-care expenditure may help minimize increases in breast cancer mortality during economic crises.
\end{abstract}

\section{Introduction}

$T^{\mathrm{h}}$ he present economic crisis has profoundly affected the European Union (EU), with persistently high unemployment rates and concerns over the effects of such crises on population health. ${ }^{1}$ In response to the economic crisis, several governments have implemented fiscal consolidation measures. In countries that have seen unemployment rates increase substantially from 2006 (before the crisis) to 2013 (Figure 1), public-sector spending cuts have been sizeable, which, in turn, have contributed to further rises in unemployment. $^{2}$ On an individual level, long-term unemployment and loss of employment have been linked to a multitude of unhealthy behaviours, increased suicide rates and reduced access to care. ${ }^{3-5}$ Recent work has also demonstrated that fiscal consolidation measures are associated with significant reductions in publicsector expenditure on health care (PSEH). ${ }^{6}$ Such changes raise the question of how economic variations, outside and within crises, affect health outcomes.

Ecological studies exploring health-economic trends have thus far focussed predominantly on non-neoplastic outcomes, such as suicide rates, cardiovascular disease incidence and all-cause mortality. ${ }^{7-11}$ As a result, insights into the relationship between macroeconomic changes and cancer remain limited.

Breast cancer is the largest cause of female cancer mortality in the EU, with an estimated 89000 deaths in 2013. ${ }^{12}$ Deprivation and lower socio-economic status (SES), to which long-term unemployment may contribute, ${ }^{13}$ have been associated with increased breast cancer mortality in individuals. ${ }^{14}$ In the short term, lower SES is associated with increased cancer mortality ${ }^{15}$ due in part to reduced access to treatment. ${ }^{16}$ In the long term, more deprived women are more likely to be diagnosed at a later stage owing to a lower likelihood of attending screening, for example, ${ }^{17}$ as well as being less likely to attend follow-up, and thus entailing a greater risk of mortality. Recent work, for example, has shown that substantial reductions in 5 -year breast cancer mortality can be achieved by eliminating deprivation differences in stage at diagnosis. ${ }^{14}$

Given this relationship between long-term unemployment, low SES and breast cancer mortality, we evaluated, at the macroeconomic level, how changes in unemployment and PSEH varied with female breast cancer mortality, over a 20 -year period in the EU. Unemployment changes and PSEH were chosen primarily for their reliability as macroeconomic indicators, high data availability and, 


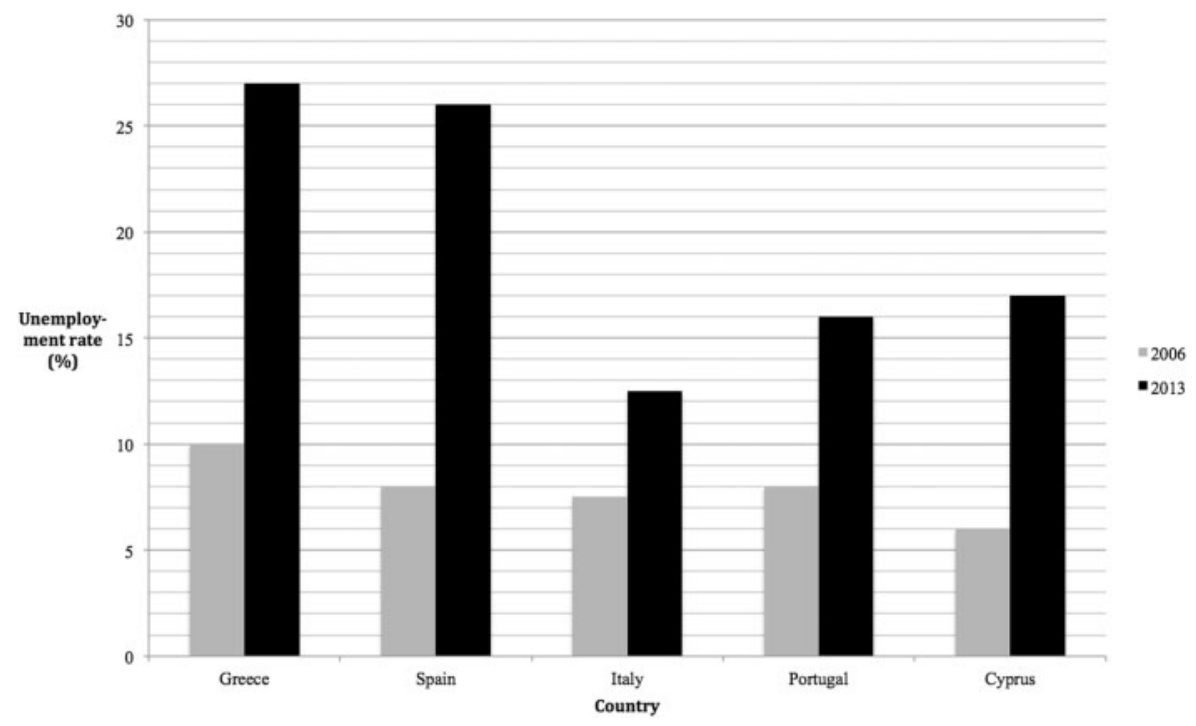

Figure 1 Unemployment rate (\%) in selected EU countries, 2006 and 2013. Unemployment rates have risen from 2006 to 2013 in these countries. Source: European Commission. EUROSTAT. European Commission, 2013 (Accessed December 29, 2013, atepp.eurostat.ec.europa.eu).

in the case of unemployment, the ability to capture actual changes in circumstances at the level of the individual. Moreover, there is evidence to suggest a link between changes in unemployment and health outcomes at the aggregate and individual levels. ${ }^{2,4}$ In what we believe to be the first study of its kind, we aimed to provide a better understanding of the link between macroeconomic changes and breast cancer.

\section{Methods}

\section{Data collection}

Female breast cancer mortality data (deaths per 100000) were obtained from the World Health Organization (WHO) mortality database. $^{18}$ Data were available for years 1990-2009. WHO mortality data are obtained via death certification and are annually collected from civil registration systems of WHO member states. The quality of the data has been evaluated by the WHO. ${ }^{19}$ Macroeconomic data were obtained from the World Bank's Development Indicators and Global Development Finance 2013 edition. $^{20}$ Public-sector debt as a percentage of gross domestic product (GDP) data was obtained from the International Monetary Fund (IMF) Historical Public Debt Database. ${ }^{21}$ Data were analysed for the $27 \mathrm{EU}$ member states (Table 1), but only for the years when these countries were members of the EU. Because our analysis explored 1990-2009, Croatia-which joined in the EU in 2013 — was excluded. Unemployment, as defined by the World Bank (data code: SL.UEM.TOTL.ZS), ${ }^{20}$ was taken to be the share of the labour force that is without work but available and seeking employment. PSEH (data code: SH.XPD.PUBL.ZS) was measured as a percentage of GDP, and was defined by the World Bank as including all rent and capital spending from government budgets (central and local), external borrowings and grants (including donations from international agencies and non-governmental organizations) and social (or compulsory) health insurance funds.

\section{Statistical analysis}

Multivariate regression analysis was used to assess the relationship between breast cancer mortality (response variable) and unemployment (predictor variable). To ensure that results were not driven by extreme observations for certain countries, a fixed-effects approach was used in the regression models, including 27 dummy variables for the 27 countries in the dataset. Doing this means that the model
Table 1 Unemployment and breast cancer mortality levels in the EU, 2009

\begin{tabular}{|c|c|c|c|}
\hline Country & $\begin{array}{l}\text { Year } \\
\text { joining EU }\end{array}$ & $\begin{array}{l}\text { Unemployment } \\
2009\end{array}$ & $\begin{array}{l}\text { Breast cancer } \\
\text { mortality } 2009\end{array}$ \\
\hline Austria & 1995 & 4.8 & 15.3 \\
\hline Belgium & 1973 & 7.9 & 19.1 \\
\hline Bulgaria & 2007 & 6.8 & 14.9 \\
\hline Cyprus & 2004 & 5.3 & 0 \\
\hline Czech Republic & 2004 & 6.7 & 13.6 \\
\hline Denmark & 1973 & 6 & 19.4 \\
\hline Estonia & 2004 & 13.8 & 15.5 \\
\hline Finland & 1995 & 8.2 & 13.4 \\
\hline France & 1957 & 9.1 & 16.6 \\
\hline Germany & 1957 & 7.7 & 16.3 \\
\hline Greece & 1981 & 9.5 & 14 \\
\hline Hungary & 2004 & 10 & 19.6 \\
\hline Ireland & 1973 & 11.7 & 19.1 \\
\hline Italy & 1957 & 7.8 & 15.8 \\
\hline Latvia & 2004 & 17.1 & 17.8 \\
\hline Lithuania & 2004 & 13.7 & 17 \\
\hline Luxembourg & 1957 & 5.1 & 16.3 \\
\hline Malta & 2004 & 6.9 & 24.5 \\
\hline Netherlands & 1957 & 3.4 & 18.5 \\
\hline Poland & 2004 & 8.2 & 14.1 \\
\hline Portugal & 1986 & 9.5 & 13.9 \\
\hline Romania & 2007 & 6.9 & 15.7 \\
\hline Slovak Republic & 2004 & 12.1 & 5.2 \\
\hline Slovenia & 2004 & 5.9 & 16.8 \\
\hline Spain & 1986 & 18 & 12.2 \\
\hline Sweden & 1995 & 8.3 & 13.1 \\
\hline United Kingdom & 1973 & 7.7 & 17.3 \\
\hline
\end{tabular}

Sources: Breast cancer mortality per 100000 . World Health Organization Mortality Data and Statistics; http://www.who.int/ healthinfo/statistics/mortality/en/index.html

Economic and population data. World Bank Development Indicators 2013; http://data.worldbank.org/data-catalog/worlddevelopment-indicators

evaluates mortality changes within individual countries while holding constant time-invariant differences between countries including higher predispositions to breast cancer, as well as political, cultural and structural differences. Such time-invariant heterogeneity was also controlled for by using a panel-data approach to compare unemployment rates or PSEH with the mortality rates in each country; something that aggregate, time-series analyses fail to do. This conservative modelling approach makes the data more 
comparable. The demographic structure of the selected countries was controlled for by incorporating total population size in addition to the percentage of the population aged $>65$ and $<15$ years old into the model. We used the Cook-Weisberg test ${ }^{22}$ to assess for and to confirm heteroskedasticity (where subsamples have different distributions) in the data used. As a consequence of this heteroskedasticity, robust standard errors were included in the regression models. This methodology has been widely used in similar health-economics studies, and is regarded as a statistically robust and conservative approach., $8,23,24$

Our fixed effects statistical model was therefore

$$
\mathrm{H}_{i, t}-\mathrm{H}_{i, 0}=\alpha+\left(\mathrm{U}_{i, t}-\mathrm{U}_{i, 0}\right) \beta+\eta t+\varepsilon_{i, t},
$$

where $i$ is country and $t$ is year; $\mathrm{H}$ is the health metric (breast cancer mortality); $\mathrm{U}$ is the measure of unemployment; $\alpha$ represents the population structure of the country being analysed, $\eta$ is a dummy variable for each country included in the regression model and $\varepsilon$ is the error term.

To determine how PSEH modified the association between unemployment and breast cancer mortality, the analysis was re-run keeping unemployment as the predictor variable, with increases in PSEH introduced as a control variable. The analysis was then repeated using PSEH as the predictor variable and breast cancer mortality as the response variable.

We conducted 1-, 2-, 3-, 4-, 5- and 10-year time-lag multivariate analyses to quantify the long-term effects of changes in unemployment may have on breast cancer mortality. Several robustness checks were also conducted; these are detailed in the results section.

Stata SE version 12 was used for the analysis (Stata Corporation, Texas, USA).

\section{Results}

\section{Unemployment}

Table 2 shows the results of five regression models for $27 \mathrm{EU}$ countries between 1990 and 2009 after correcting for population size, demographic structure and country-specific differences in infrastructure.

A $1 \%$ rise in unemployment was associated with a statistically significant increase in breast cancer mortality $[P<0.0001$, coefficient $(R)=0.1829,95 \%$ confidence interval (CI) 0.0978-0.2680]. Using current EU population estimates, ${ }^{25}$ this correlated with 1148 additional deaths across the region for each $1 \%$ rise in

Table 2 Multiple regression and lag analysis

\begin{tabular}{lllll}
\hline $\begin{array}{l}\text { Number of years } \\
\text { after 1\% rise in } \\
\text { unemployment }\end{array}$ & Coefficient & $P$ value & $\begin{array}{l}\text { Lower } \\
\text { confidence } \\
\text { interval }\end{array}$ & $\begin{array}{l}\text { Upper } \\
\text { confidence } \\
\text { interval }\end{array}$ \\
\cline { 2 - 5 } & & & 0.0978 & 0.2680 \\
\hline Year 0 (year of change & 0.1829 & 0.0000 & 0.0978 & \\
$\quad$ in unemployment) & & & & 0.3130 \\
Year 1 & 0.2232 & 0.0000 & 0.1333 & 0.3296 \\
Year 2 & 0.2326 & 0.0000 & 0.1357 & 0.3606 \\
Year 3 & 0.2568 & 0.0000 & 0.1531 & 0.3874 \\
Year 4 & 0.2798 & 0.0000 & 0.1721 & 0.3651 \\
Year 5 & 0.2649 & 0.0000 & 0.1647 & 0.2663 \\
Year 10 & 0.1825 & 0.0000 & 0.0987 & \\
\hline
\end{tabular}

The impact of annual changes in unemployment on breast cancer mortality, controlling for population size, population structure (proportion of population $<14$ years of age, proportion of population $>65$ years of age) and controlling for inter-country differences in health-care infrastructure in addition to political, cultural and structural differences (by introducing dummy variables for each of the $27 \mathrm{EU}$ countries). unemployment, without incorporating lagged or long-term effects of changes in unemployment. Lag analysis showed a continued increase in breast cancer mortality at 1 year $(P<0.0001$, $\mathrm{R}=0.2232, \quad 95 \% \quad$ CI $\quad 0.1333-0.3130) ; \quad 3$ years $\quad(P<0.0001$, $\mathrm{R}=0.2568, \quad 95 \% \quad \mathrm{CI} \quad 0.1531-0.3606) ; \quad 5$ years $\quad(P<0.0001$, $\mathrm{R}=0.2649$, 95\% CI $0.1647-0.3651)$; and 10 years $(P<0.0001$, $\mathrm{R}=0.1825, \quad 95 \%$ CI $0.0987-0.2663)$ after an increase in unemployment.

\section{Public-sector expenditure on health care}

Including PSEH (measured as a percentage of GDP) as a control in the above multivariate regression analyses removed the significant association between unemployment and breast cancer mortality $(P=0.063, \mathrm{R}=0.080,95 \% \mathrm{CI}-0.004$ to 0.163$)$. Notably, the sample size and degrees of freedom in the analysis were also decreased.

Multiple regression analysis, controlling for population size, demographic structure and country-specific differences in infrastructure, showed that a $1 \%$ rise in PSEH was associated with a statistically significant decrease in breast cancer mortality $(P<0.0001, \mathrm{R}=-1.28,95 \% \mathrm{CI}-1.67$ to -0.877$)$.

\section{Robustness checks}

To determine the robustness of our findings we conducted a series of further analyses. First, we introduced additional economic variables into the model to better isolate the impact of unemployment, controlling for inflation, government debt as a percentage of GDP, interest rates and changes in GDP per capita (Table 3). Unemployment rises continued to be associated with increases in breast cancer mortality $(P=0.0307, \mathrm{R}=0.1021,95 \%$ CI 0.0096 0.1946). Second, we introduced additional infrastructure variables, controlling for urbanization, access to water, nutrition (mean calorie intake). Despite a reduction in sample size and loss of degrees of freedom due to the additional controls, unemployment rises continued to be associated with increases in breast cancer mortality $(P=0.0001, \mathrm{R}=0.1967,95 \%$ CI $0.0978-0.2955)$. Third, we controlled for differences in total spending on health care per capita between countries (measured in US dollars; composed of public and private sources of spending). Unemployment rises continued to be associated with increases in breast cancer mortality $(P=0.0081, \mathrm{R}=0.0999,95 \%$ CI $0.0262-0.1736)$. Finally, we re-ran the original multivariate regression using an alternate source breast cancer mortality data-the EUREG European Cancer Registry. ${ }^{26}$ Unemployment continued to be associated with increases in breast cancer mortality $(P=0.0011, \mathrm{R}=0.1551,95 \%$ CI $0.0625-$ $0.2476)$.

\section{Discussion}

\section{Findings}

We have shown that rises in unemployment in the EU are associated with increased breast cancer mortality both in the short- and longterm. This association remained after controlling for infrastructure and economic indicators, but was removed when accounting for PSEH. We have also shown that reduced PSEH is associated with increased breast cancer mortality.

\section{Possible mechanisms}

The mechanism through which unemployment leads to worsening breast cancer mortality is not yet established in the literature. We observed both short- and long-term associations between loss of employment and breast cancer mortality in our time-lag analyses. We propose that the documented relationship between long-term unemployment, low SES and breast cancer ${ }^{15-17,27-29}$ may be the means by which unemployment changes have a 'scarring' effect on 
Table 3 Robustness checks

\begin{tabular}{|c|c|c|c|c|c|c|}
\hline $\begin{array}{l}\text { Robustness } \\
\text { check }\end{array}$ & $\begin{array}{l}\text { Controls used in multiple } \\
\text { regression }\end{array}$ & $\begin{array}{l}\text { Total number of } \\
\text { controls in } \\
\text { regression }\end{array}$ & Coefficient & $P$ value & $\begin{array}{l}\text { Lower confidence } \\
\text { interval }\end{array}$ & $\begin{array}{l}\text { Upper } \\
\text { confidence } \\
\text { interval }\end{array}$ \\
\hline $\begin{array}{l}\text { Economic } \\
\text { controls }\end{array}$ & $\begin{array}{l}\text { Original analysis controls and } \\
\text { changes in GDP per capita, } \\
\text { inflation, government debt as } \\
\text { a percentage of GDP, interest } \\
\text { rates }\end{array}$ & 34 & 0.1021 & 0.0307 & 0.0096 & 0.1946 \\
\hline $\begin{array}{l}\text { Health } \\
\text { spending } \\
\text { per capita }\end{array}$ & $\begin{array}{l}\text { Original analysis controls and } \\
\text { health spending per capita } \\
\text { (dollars) }\end{array}$ & 31 & 0.0999 & 0.0081 & 0.0262 & 0.1736 \\
\hline $\begin{array}{l}\text { EUREG } \\
\text { database }\end{array}$ & $\begin{array}{l}\text { Original analysis controls, using } \\
\text { European Registry cancer } \\
\text { database }\end{array}$ & 30 & 0.1551 & 0.0011 & 0.0625 & 0.2476 \\
\hline
\end{tabular}

Multiple regression analyses were re-run using the controls in the original analysis (population size, proportion of population $>65$ years of age, proportion $<14$ and 27 country controls), in addition to those mentioned in the table below. The data show the impact of a $1 \%$ rise in unemployment, on breast cancer mortality, using the mentioned controls.

mortality that persists long after initial periods of unemployment rises.

In the short to medium term, we suggest a number of mechanisms through which mortality may relate to changes in unemployment. Job loss has been associated with high levels of psychological problems and harmful behaviours, in part due to reduced access to health care, which can arise through an inability to pay for transport, for example. ${ }^{4-6}$ As a consequence of this, treatment or diagnosis of breast cancer may well be delayed, thus entailing an increased risk of mortality. In our analyses, the association between unemployment and breast cancer mortality was present even when controlling for urbanization, access to water and nutrition (calorie intake).

Our analyses also implicate PSEH as an important moderator of the relationship between change in unemployment and breast cancer mortality. Consistent with country-comparison study results ${ }^{30}$ we found PSEH to be closely associated with breast cancer mortality. The breast cancer care pathway is multidisciplinary and can be costly, involving screening, radiotherapy, pharmacotherapy and breast surgery, with associated reductions in mortality. ${ }^{31-34}$ Therefore, by increasing or maintaining access to health care for those who have lost their jobs, elevations in PSEH may negatively influence rates of breast cancer mortality.

\section{Policy implications}

Collectively, these findings have several policy implications. First, from a population health perspective, we highlight the need for public health input to economic policy development, to protect and maintain population health, specifically, in this case, breast cancer mortality. Based on our analyses, this could be achieved through policies supporting re-employment or those aiming to maintain or increase PSEH during economic downturns and rises in unemployment. The need for this is highlighted by economic forecasts that suggest that in EU member states such as the UK, unemployment rates are unlikely to return to pre-recession levels until after $2017 .^{35}$

Second, our work suggests that policy interventions and fiscal consolidation measures exacerbating unemployment while also reducing PSEH or failing to compensate for reductions in privatesector and out-of-pocket health-care expenditure, ${ }^{6,36}$ are likely to see reductions in total health-care expenditure and, subsequently, increases in breast cancer mortality in the EU. Indeed, some economists have suggested that recent European fiscal consolidation policies have been economically damaging. ${ }^{37,38}$ Our results extend this argument to the public-health sphere. Moreover, the 'troika' [the EU, the European Central Bank (ECB) and the IMF] have influenced the economic and fiscal policies of EU member states most affected by the economic crisis (Cyprus, Greece, Ireland, Portugal and Spain) with a view to control public-sector debt levels through implementation of fiscal consolidation programmes, frequently at the expense of higher unemployment. ${ }^{39}$ Our findings lead us to question, from a public-health perspective, the merit of these policies.

\section{Limitations and advantages of the study}

It is important to note the limitations of this study. First, we evaluated population health outcome and economic trends at the multinational level when, in fact, important unemployment variations exist at regional and subnational levels. ${ }^{29}$ Although national studies in this sphere have been conducted, our analysis provides important insights across a European population, serving of relevance to multinational policy development by agencies such as the IMF, EU and ECB. We were also unable to model intra-year variations in the level of unemployment. Second, we were unable to control for specific aspects of the breast cancer care pathway such as screening, which, as discussed, is likely to play a role in the identified association. Third, for reasons of data availability, we were unable to analyse the effects of the recent Great Recession from 2010 onwards. However, in addition to recessions during the early 1990s and 2000s, our analysis was still able to capture the effects of the earlier stages of the Great Recession during which unemployment levels in some countries peaked. Finally, because breast cancer is not as aggressive as some other cancers, a longitudinal panel study that accounted for secular, falling breast cancer mortality rates during the study period would help elucidate the empirical induction period required to see the impact that changes in unemployment and PSEH have on avoidable breast cancer mortality.

Nevertheless, our study investigated the effect of unemployment rises on breast cancer mortality with 30 controls for inter-country variations, using numerous robustness checks. These checks and the incorporation of robust standard errors allowed us to account for the heterogeneity in the unemployment dataset owing to differences in the way that countries measured unemployment rates, along with factors such as underemployment or social programmes (for example, back-to-work initiatives or programmes that see people move from employment into education or training) that may otherwise have hidden or suppressed actual unemployment rates. As such, these checks allowed us to satisfactorily identify trends over time across the region. 


\section{Conclusions}

The 2009 recession led to a rapid decline in the GDP of almost all EU member states, ${ }^{25}$ and the economies of many countries have yet to recover. This event has raised the question of how macroeconomic variations may impact cancer outcomes. Our study has shown that increases in aggregate unemployment are associated with significantly worse breast cancer mortality in the EU, a link that may be moderated by changes in PSEH. Our study may thus be seen as a first examination of the important breast cancer-related consequences of the economic crisis. Policy interventions and austerity measures, which may increase unemployment and reduce $\mathrm{PSEH}$, are a key concern, possibly presenting additional barriers to breast cancer management.

Conflicts of interest: None declared.

\section{Key points}

- We used cross-country panel-data multivariate regression analysis to examine how increases in aggregate unemployment varied with breast cancer mortality in the EU.

- We then examined how PSEH modified this association, and also examined how PSEH increases varied with breast cancer mortality in the EU.

- Increases in unemployment were associated with increases in breast cancer mortality, while controlling for PSEH removed the positive association between unemployment and breast cancer mortality. Increases in PSEH were associated with reduced breast cancer mortality.

- A likely mechanism for these associations is reduced access to care in times of high unemployment and reduced healthcare spending.

- To help avoid reductions in breast cancer mortality during economic downturns, clinicians should facilitate access to care for the unemployed, and policymakers should seek to bolster employment levels and protect or, possibly, increase PSEH to maintain total health-care expenditure.

\section{References}

1 Horton R. The global financial crisis: an acute threat to health. Lancet 2009;373: 355-6.

2 Stuckler D, Basu S. The Body Economic: Why Austerity Kills. New York City, USA: Basic Books, 2013.

3 Paul K, Moser K. Unemployment impairs mental health: meta-analyses. J Vocational Behav 2009;74:264-82.

4 Morris J, Cook D, Shaper G. Loss of employment and mortality. BMJ 1994;308: $1135-9$.

5 Ungváry G, Morvai V, Nagy I. Health risk of unemployment. Central Eur JOEM 1999;5:91-112.

6 Reeves A, McKee M, Basu S, Stuckler D. The political economy of austerity and healthcare: Cross-national analysis of expenditure changes in 27 European nations 1995-2011. Health Policy 2014;115:1-8.

7 Barr B, Taylor-Robinson D, Scott-Samuel A, et al. Suicides associated with the 2008-10 economic recession in England: time trend analysis. BMJ 2012;345: e5142.

8 Stuckler D, Basu S, Suhrcke M, et al. The public health effect of economic crises and alternative policy responses in Europe: an empirical analysis. Lancet 2009;374: 315-23.

9 Stuckler D, Basu S, Suhrcke M, McKee M. The health implications of financial crisis: a review of the evidence. Ulster Med J 2009;78:142-5.

10 Tapia-Granados JA. Increasing mortality during the expansions of the US economy, 1900-1996. Int J Epidemiol 2005;34:1194-202.
11 Gerdtham U-G, Ruhm CJ. Deaths rise in good economic times: evidence from the OECD. Econ Hum Biol 2006;4:298-316.

12 Malvezzi M, Bertuccio P, Levi F, et al. European cancer mortality predictions for the year 2013. Ann Oncol 2013;24:792-800.

13 Klein-Hesselink DJ, Spruit IP. The contribution of unemployment to socioeconomic health differences. Int J Epidemiol 1992;21:329-37.

14 Rutherford MJ, Hinchliffe SR, Abel GA, et al. How much of the deprivation gap in cancer survival can be explained by variation in stage at diagnosis: an example from breast cancer in the East of England. Int J Cancer 2013;133: 2192-200.

15 Akinyemiju TF, Soliman AS, Copeland G, et al. Trends in breast cancer stage and mortality in Michigan (1992-2009) by race, socioeconomic status and area healthcare resources. PLoS One 2013;8:e61879.

16 Weissman JS, Stern R, Fielding SL, Epstein AM. Delayed access to health care: risk factors, reasons, and consequences. Ann Intern Med 1991;114: 325-31.

17 Adams J, White M, Forman D. Are there socioeconomic gradients in stage and grade of breast cancer at diagnosis? Cross sectional analysis of UK cancer registry data. BMJ 2004;329:142.

18 World Health Organization. Mortality database. World Health Organization, 2013. Available at: http://apps.who.int/healthinfo/statistics/mortality/whodpms (26 December 2013, date last accessed).

19 Mathers CD, Fat DM, Inoue M, et al. Counting the dead and what they died from: an assessment of the global status of cause of death data. Bull World Health Organ 2005;83:171-7.

20 World Bank. Development Indicators \& Global Development Finance 2013. World Bank, 2013. Available at: http://data.worldbank.org/data-catalog/worlddevelopment-indicators (26 December 2013, date last accessed).

21 International Monetary Fund. Historical Public Debt Database. International Monetary Fund, 2013. Available at: http://www.imf.org/external/pubs/ft/wp/2010/ wp10245.pdf (26 December 2013, date last accessed).

22 Cook RD, Weisberg S. Diagnostics for heteroscedasticity in regression. Biometrika 1983;70:1-10.

23 Davidson R, MacKinnon J. Estimation and Inference in Econometrics. New York City, USA: Oxford University Press, USA, 1993.

24 Saffer H, Chaloupka F. The effect of tobacco advertising bans on tobacco consumption. J Health Econ 2000;19:1117-37.

25 European Commission. EUROSTAT. European Commission, 2013. Available at: epp.eurostat.ec.europa.eu (26 December 2013, date last accessed).

26 International Agency for Research on Cancer. EUREG European Cancer Registry. Lyon, France: International Agency for Research on Cancer, 2013. Available at: http://eco.iarc.fr/EUREG/Default.aspx (26 December 2013, date last accessed).

27 Bradley CJ, Given CW, Roberts C. Race, socioeconomic status, breast cancer treatment and survival. J Natl Cancer Inst 2002;94:490-6.

28 Dasgupta P, Baade PD, Aitken JF, Turrell G. Multilevel determinants of breast cancer survival: association with geographic remoteness and area-level socioeconomic disadvantage. Breast Cancer Res Treat 2012;132:701-10.

29 Lyratzopoulos G, Barbiere JM, Rachet B, et al. Changes over time in socioeconomic inequalities in breast and rectal cancer survival in England and Wales during a 32-year period (1973-2004): the potential role of health care. Ann Oncol 2011;22:1661-6.

30 Ades F, Senterre C, de Azambuja E, et al. Discrepancies in cancer incidence and mortality and its relationship to health expenditure in the 27 European Union member states. Ann Oncol 2013;24:2897-902.

31 16-year Mortality from breast cancer in the UK Trial of Early Detection of Breast Cancer. Lancet 1999;353:1909-14.

32 Davies C, Godwin J, Gray R, et al. Relevance of breast cancer hormone receptors and other factors to the efficacy of adjuvant tamoxifen: patient-level meta-analysis of randomised trials. Lancet 2011;378:771-84.

33 Slamon D, Eiermann W, Robert N, et al. Adjuvant trastuzumab in HER2-positive breast cancer. N Engl J Med 2011;365:1273-83.

34 Baselga J, Cortés J, Kim SB, et al. Pertuzumab plus trastuzumab plus docetaxel for metastatic breast cancer. N Engl J Med 2012;366:109-19.

35 Office for Budget Responsibility. Economic and Fiscal Outlook. London, UK: Office for Budget Responsibility, 2011. 
36 Ball L, Leigh D, Loungani P. Painful medicine. Finance Dev 2011;48:20-3.

37 Baily MN. Europe's So-called "Expansionary Contraction” Has Not Worked in Practice. Brookings Institution, 2012, Available at: http://www.brookings.edu/ research/opinions/2012/02/expansionary-contraction-baily (9 March 2014, date last accessed).
38 Perotti R. The "Austerity Myth": gain without pain? In: Alesina A, Giavazzi F, editors. Fiscal Policy after the Financial Crisis Chicago, USA: University of Chicago Press, 2013.

39 Sugawara N. Fiscal adjustment in Greece under the financial rescue programme: the distributional effects on Greek households. Appl Econ Lett 2012;19:1071-4.

European Journal of Public Health, Vol. 25, No. 2, 335-339

(C) The Author 2014. Published by Oxford University Press on behalf of the European Public Health Association. All rights reserved. doi:10.1093/eurpub/cku069 Advance Access published on 6 June 2014

\title{
Increasing disability-free life expectancy among older adults in Palestine from 2006 to 2010
}

\author{
Henrik Brønnum-Hansen¹, Mohammed Duraidi², Khaled Qalalwa², Bernard Jeune ${ }^{3}$ \\ 1 Department of Public Health, Faculty of Health Sciences, University of Copenhagen, Øster Farimagsgade 5, \\ Copenhagen, Denmark \\ 2 Palestinian Central Bureau of Statistics, Ramallah, Palestine \\ 3 Epidemiology, Institute of Public Health, and Danish Ageing Research Centre, University of Southern Denmark, Odense, \\ Denmark
}

Correspondence: Henrik Brønnum-Hansen, Department of Public Health, Faculty of Health Sciences, University of Copenhagen, Øster Farimagsgade 5, 1014 Copenhagen, Denmark, Tel: +45 353279 74, e-mail: henrik.bronnum-hansen@sund.ku.dk

\begin{abstract}
Background: The population of Palestine comprises almost 200000 Palestinians aged 60 or older. The purpose of the study was to estimate disability-free life expectancy for Palestinians living in the West Bank and Gaza Strip and to evaluate changes from 2006 to 2010. Methods: The study combined mortality data and prevalence of activity limitation derived from the Palestinian Family Health Surveys carried out in 2006 and 2010. Based on questions about the ability to perform five basic daily activities, disability-free life expectancy was estimated. Changes between 2006 and 2010 were decomposed into contributions from changes in mortality and disability. Results: Life expectancy at age 60 increased from 17.1 years in 2006 to 17.3 years in 2010 for men and from 18.7 years to 19.0 years for women. Disability-free life expectancy increased significantly, by 1.3 years for 60 -year-old men (from 12.8 years to 14.1 years) and 1.8 years for 60 -year-old women (from 12.6 years to 14.4 years). This increase was seen in the Gaza Strip as well as in the West Bank. While the modest contribution of the mortality effect did not differ between gender and regions, the strong contributions from the disability effects varied, being greatest for women in the Gaza Strip. Conclusion: The significant increase in disability-free life expectancy for both genders is remarkable and, to our knowledge, not seen in other low-income countries. This change may be due to decreasing incidence of disability and greater recovery from disability as a result of better prevention, care and rehabilitation of chronic diseases.
\end{abstract}

\section{Introduction}

$T^{1}$ he number of Palestinians living in the continuously shrinking land of Palestine in 2012 is 4.4 million, of which 2 million are refugees, the majority living in camps. ${ }^{1}$ Since the state of Israel was established in 1948, the Palestinian population has been living under war conditions, occupation or dislodged from their native soil. The situation has deteriorated because Israel aggravates the conflict by extending restrictions on movement and access to resources, markets and health services, resulting in continuing dependency of donor financing. ${ }^{2}$

The imbalance between the lives of Palestinians and Israelis is striking. According to the World Bank, gross national income per capita in Palestine is 18 times less than that of Israel. ${ }^{3}$ In 2010, the unemployment rate was $23.7 \%$ in Palestine $(17.2 \%$ in the West Bank and $37.8 \%$ in the Gaza Strip) ${ }^{4}$ and $6.6 \%$ in Israel. ${ }^{5}$ Although life expectancy at birth is higher in Palestine than in some Arab countries, it is $\sim 9$ years shorter among Palestinians than Israelis, ${ }^{6}$ and regardless of which indicator for welfare and sustainability is chosen, the situation in the occupied society is unfavourable and in stark contrast to the situation in the occupying power.
The health and quality of life of the Palestinian population have been described in several papers. ${ }^{7-13}$ The mortality pattern has changed from infectious diseases to non-communicable diseases as the main causes of death. ${ }^{14}$ Today, heart disease, stroke, diabetes and cancer account for about one-half of the total deaths. Increasing urbanization has entailed a transition from a rural to an urban lifestyle with adverse changes in the risk profile. ${ }^{7}$ Smoking (among men), poor dietary habits, sedentary lifestyle and obesity are now highly prevalent among Palestinians living in Palestine (e.g. the prevalence of obesity is $\sim 40 \%)^{8,15}$ In urban areas, which represent about half of the population, diastolic blood pressure, fasting blood glucose, cholesterol and triglycerides are significantly higher than in the rural population. ${ }^{7}$ As a result, hypertension, heart diseases, the metabolic syndrome, diabetes and cancer today are common illnesses among Palestinians; for example, among the growing number of 60 -year-olds or older, $\sim 35 \%$ reported having hypertension in 2006 and $25 \%$ reported having diabetes. ${ }^{11,16}$

Recently we found that expected lifetime with chronic disease at the age of 20 increased from 2006 to 2010 both for Palestinian men and women (from 15.1 to 17.1 years for men, and from 13.6 to 14.4 years for women), in both the Gaza strip and the West Bank. ${ }^{6}$ In particular, the increase in expected lifetime with hypertension and 